\title{
Microbiome and Cervical Cancer
}

\author{
Cristina Paula Castanheira ${ }^{a}$ Mayara Luciana Sallas ${ }^{b}$ \\ Rafaella Almeida Lima Nunes ${ }^{\mathrm{b}}$ Noely Paula Cristina Lorenzic ${ }^{\mathrm{C}}$ Lara Termini $^{\mathrm{b}}$ \\ ${ }^{a}$ Department of Obstetrics and Gynecology, Conjunto Hospitalar Mandaqui, São Paulo, Brazil; ${ }^{b}$ Innovation in Cancer \\ Laboratory, Centro de Investigação Translacional em Oncologia, Instituto do Câncer do Estado de São Paulo Octavio \\ Frias de Oliveira, Hospital das Clínicas da Faculdade de Medicina da Universidade de São Paulo, São Paulo, Brazil; \\ 'Department of Gynecology, Hospital Universitário da Universidade de São Paulo, São Paulo, Brazil
}

\section{Keywords}

Microbiome $\cdot$ Cervical cancer $\cdot$ Human papillomavirus

\begin{abstract}
Persistent infection with some types of mucosal human papillomavirus (HPV) is the etiological factor for the development of cervical cancer and its precursor lesions. Besides, several cofactors are known to play a role in cervical disease onset and progression either by favoring or by preventing HPV infection and persistence. The microbiome of a healthy female genital tract is characterized by the presence of 1 or few varieties of lactobacilli. However, high-throughput studies addressing the bacterial diversity and abundance in the female genital tract have shown that several factors, including hormonal levels, hygiene habits, and sexually transmitted diseases may disrupt the natural balance, favoring the outgrowth of some groups of bacteria, which in turn may favor some pathological states. Recently, the vaginal microbiome has emerged as a new variable that could greatly influence the natural history of HPV infections and their clinical impact. In this context, changes in the vaginal microbiome have been detected in women infected with HPV and women with HPV-associated lesions and cancer. However, the role of specific bacteria groups in the development/progression or prevention/regression of HPV-associated patholo-
\end{abstract}

gies is not well understood. In this review we summarize the current knowledge concerning changes in vaginal microbiome and cervical disease. We discuss the potential functional interplay between specific bacterial groups and HPV infection outcomes.

(c) 2020 S. Karger AG, Basel

\section{Introduction}

Cervical cancer (CC) represents the fourth most frequent malignant neoplasia among women worldwide and it is a serious public health problem. In 2018, approximately 570,000 new cases and 311,000 deaths occurred, and most of them were in developing countries [1-4]. Persistent infection with human papillomavirus (HPV) types of high-oncogenic-risk HPV (hrHPV) is the main factor for the development of CC, and it has been found in $99.7 \%$ of CC samples [5]. Infection with hrHPV is highly prevalent in sexually active women. However, the occurrence of CC precursor lesions is relatively low $[6,7]$. In fact, approximately $90 \%$ of infections by hrHPV are transient and regress spontaneously [8]. A woman's risk of acquiring an infection by any type of HPV during her

\section{C.P.C., M.L.S., and R.A.L.N. contributed equally to this work.}

Lara Termini

Innovation in Cancer Laboratory, Centro de Investigação Translacional em Oncologia Instituto do Câncer do Estado de São Paulo Octavio Frias de Oliveira, Faculdade de Medicina da Universidade de São Paulo, Rua Dr. Ovídio Pires de Campos, 872-3 Andar Cerqueira César, São Paulo, SP CEP 05403-911 (Brazil)

lara.termini@hc.fm.usp.br 
lifetime is approximately $80 \%$, whereas her risk of developing CC is $0.6 \%$ [9].

Infection with hrHPV is necessary but not sufficient for CC development, and additional factors are involved in disease establishment, progression, or regression. Some of these factors, such as the viral type involved, are virus related, and others, such as individual immunity, smoking, parity, use of hormonal contraceptives, and sexual behavior, are host related [8].

Recent studies have assessed the potential relationship between the vaginal microbiome (VMB) and gynecological cancer [10]. The VMB composition may influence the local immune response and could be involved in cervical oncogenesis and HPV clearance. The VMB with a predominance of certain species of lactobacilli may have a protective role against opportunistic infections and it may represent a new therapeutic target [11]. This review will address the likely relationship between VMB composition and CC development.

\section{Vaginal Microbiome}

The human body possesses trillions of microorganisms that coexist with one another and interact with the host $[12,13]$. The concept of microbiome was first used by Lederberg and McCray [14] to designate a set of commensal, symbiotic, or pathogenic microorganisms, which share the same living space and develop a complex interaction with certain human tissues.

The first large study to address the diversity of microorganisms present in the different organs of the human body was the Human Microbiome Project (HMP), which started in 2008. In this study the microbiome composition of different parts of the body, including the lower genital tract, of 242 healthy people was analyzed [15].

In the intestine, a great diversity of microorganisms is associated with a healthy environment. However, in the healthy female genital tract there is usually just 1 or few varieties of lactobacilli $[16,17]$. After studying the vaginal flora of 396 women of different ethnicities, 5 community state types (CST) of the VMB were identified [18]. CST I, II, III, and V are comprised of a low microbial diversity dominated by Lactobacillus (L) crispatus, L. gasseri, L. iners, and $L$. jensenii, respectively. In contrast, CST IV is formed by a reduction of lactobacilli and a great diversity of bacterial vaginosis (BV)-related bacteria, which are primarily anaerobic bacteria. The most frequently detected bacteria are Gardnerella vaginalis, Megasphaera, Sneathia, and Prevotella species. The VMB composition is dynamic and there is a frequent transition from one microbiome to another in the same woman throughout her life, mainly from CST III to IV [19, 20].

The VMB composition is influenced by various factors, such as ethnicity, hormonal alterations, sexual activity, and hygiene habits, as well as lactation, diabetes mellitus, stress, and dietary factors [20-22]. Some studies have shown that the VMB differs in women of different ethnicities. These data are important given that the environments dominated by BV-related bacteria are more associated with sexually transmitted infections [23, 24]. Other studies have demonstrated that African-American and Hispanic women exhibit a VMB in which bacteria other than Lactobacillus spp. predominate [23, 25, 26]. BV can affect over $50 \%$ of the women in sub-Saharan Africa [27-29]. It has become the most prevalent alteration in women of reproductive age. Such studies have implies that differences in VMB in women of different races may partly explain the differing incidence rates of $\mathrm{BV}$ and sexually transmitted infections among diverse ethnicities. Such diversity may be related to the genetic differences among races including a few mitochondrial DNA haplotypes. This reveals the importance of genetic factors in determining the microbiome of individuals, making them more or less prone to diseases [26].

The sex hormones interfere with VMB composition, regulating the release of proinflammatory cytokines, chemokines, and AMP contributing towards the selection of vaginal microbial species. Estrogen, in particular, has been implicated in the passage to a lactobacillus-rich microbiome during puberty and inversely poor during menopause [30].

Estrogen in the vaginal epithelium leads to its maturation and proliferation, as well as to the accumulation of glycogen, which is needed for a lactobacillus-rich environment. After menopause, the decline in estrogen production is accompanied by a decrease in lactobacilli and a predominance of anaerobes $[21,30]$. The lactobacilli are believed to directly metabolize glycogen to form the lactic acid responsible for acidification of the environment and maintenance of the lactobacilli. This concept was abandoned following identification of the a-amylase enzyme in mature vaginal epithelium which is under estrogen action. It was demonstrated that this enzyme catabolizes glycogen generating simple sugars such as maltose, maltotriose, maltotetraose, and $\alpha$-dextrins, which favor the formation of lactobacilli colonies [31].

During the reproductive age, it has been observed that a healthy vaginal microbiota amplifies the fluctuation of local immune responses in synchronicity with the hor- 
monal alterations of the menstrual cycle [32]. Variations in the vaginal flora composition during the menstrual cycle as a consequence of variations in estrogen and progesterone levels have been demonstrated [20]. In the phases in which estrogen declines as in menopause, a decrease in lactobacilli is observed, which can be reverted with estrogen replacement therapy [21].

The use of hormonal contraceptives has also been shown to influence the vaginal flora composition, reducing the incidence, prevalence and recurrence of BV episodes [33]. Additionally, sexual activity is a factor that seems to contribute to a reduction of the lactobacillus population, favoring bacterial diversity [34]. Interestingly, vaginal douching increases the risk of $\mathrm{BV}$, thereby demonstrating the influence of douching in the vaginal ecosystem [35].

Nicotine and its main metabolite, i.e., cotinine, are found in the cervical mucus of women and in the semen of men who smoke [36]. It has been shown that, in hrHPV-infected cells, tobacco smoke induces an increase in oncogene E6 transcription, leading to a decrease in p53 activity and levels [37], which may facilitate the development of squamous cell carcinoma [38, 39]. It is worth noting that CST IV was increased in women who smoked [40].

$\mathrm{BV}$ (CST IV) is characterized by changes in the vaginal flora, including reduced lactobacilli and a high bacterial diversity [41]. BV has been associated with inflammatory pelvic disease, a higher risk of miscarriage, preterm labor, and a greater risk of acquiring sexually transmitted diseases, including HIV [9]. The diagnosis can be made based on clinical criteria, following the Amsel classification. According to this, a BV diagnosis requires fulfillment of 3 of the following 4 criteria: fluid or bullous white discharge, presence of clue cells established directly under a microscope or through microscopic examination of a Gram-stained smear from genital discharge, a vaginal $\mathrm{pH}$ over 4.5 , and a positive amine test (fishy odor produced by the addition of 2 drops of $10 \%$ potassium hydroxide to the vaginal discharge) $[26,42]$. Another common diagnostic method is the microscopic classification, which analyzes different types of bacterial morphologies by Gram staining of Lactobacillus spp., Gardnerella spp., and Mobiluncus spp. If the stained discharge receives a score from 0 to 3 , the vaginal flora is normal; if the score is $4-6$, it is intermediate; and if it is $7-10$ it is characterized BV [26, 43].

Even though we recognize the merit of such classifications, they are subjective and may lead to overdiagnosis of $\mathrm{BV}$ in a significant number of asymptomatic women.
Studies utilizing molecular techniques, like PCR, for detection were able to identify other BV-related agents, such as Atopobium vaginae, Clostridiales, and Megasphaera species [26]. Next-generation sequencing techniques enabled the identification of a larger number of bacteria because they amplified the gene fragments of pathogens [44].

\section{Microbiome Composition and Cervicovaginal Microenvironment}

In humans, the cervicovaginal microbiome interacts with the local microenvironment, maintaining tissue homeostasis [45]. When this balance is broken, leading to a condition known as dysbiosis, several pathological processes, including epithelial barrier breach, abnormal cellular proliferation, genome instability, angiogenesis, chronic inflammation, and metabolic dysregulation can be triggered [17].

\section{Microbiome and Host Defenses}

Several defense mechanisms act to protect the female genital tract against infectious agents. These include the mucosal epithelial barrier, mucus, lactic acid secretion, and the immune response. From this perspective, the vaginal mucosa is a barrier that provides protection against invading pathogens as a consequence of the interaction among its epithelial cells, the immune system, and colonizing microorganisms $[46,47]$.

The major protective mechanism associated with lactobacilli is their ability to produce lactic acid and maintain a local $\mathrm{pH}$ lower than 4.5 , which is harmful to most pathogens, as well as to produce bacteriocins, which inhibit or eliminate pathogens transmitted sexually [48]. Besides, lactobacilli may form microcolonies which adhere to the epithelial cells, preventing the adhesion of pathogens and their ability to trigger host defenses [49]. A healthy vaginal microbiota has also been associated with an increased expression of defensins, which are vaginal antimicrobial peptides (AMP) that prevent binding of specific pathogen proteins to female genital tract cells. Thus, AMP levels were found to be decreased in women with BV [50,51]. The expression of other types of AMP, such as the secretory leukocyte protease inhibitor (SLPI), is thought to be correlated with BV-related bacteria [52]. Increased concentrations of SLPI in were reported in healthy women [53], while women with BV demonstrated lower concentrations [54]. 
Moreover, a possible mechanism for vaginal dysbiosis is an increase in the production of proinflammatory cytokines and chemokines associated with an increase in pathogenic microbial diversity, which contributes to the additional recruitment of immune cells and amplification of the inflammatory response [30].

\section{Microbiome, Immune Response, and Cervical}

Alterations

$\mathrm{BV}$ is associated with the induction of local inflammation $[25,55]$. One important factor is lactic acid depletion and, consequently, the reduction of its anti-inflammatory effects. It was shown that lactic acid induced an anti-inflammatory condition and inhibited inflammation elicited by toll-like receptor (TLR) agonists. Besides that, lactic acid triggers the interleukin (IL)-1 pathway through production of its antagonist IL-1 receptor antagonist (IL$1 \mathrm{Ra})$ [56]. In contrast, treatment with a vaginal microbiota metabolite mixture corresponding to BV increased the TLR-induced production of proinflammatory cytokines such as TNF- $\alpha$ and decreased the production of RANTES and interferon- $\gamma$-induced protein 10 (IP-10) [57].

It is suggested that BV-related inflammation is mainly due to high proinflammatory cytokines levels and not to cervical immune cell recruitment. A study comparing women with CC or dysplasia and women without neoplasia showed that an environment with non-Lactobacillus dominance was characterized by proinflammatory (IL$36 \gamma$ ), chemotactic (IP10, MIP1 $\beta$, and RANTES), hematopoietic (FLT3 ligand), and adaptive immune (IL-2, IL-4, and soluble CD40 ligand) cytokines, therefore, correlating dysbiosis, inflammation, and CC [25].

A cohort study including asymptomatic young South African women showed that cervicovaginal environment modifications, including alterations in vaginal acidity and the cytokine profile, can be associated with the local microbial pattern and that high-diversity bacterial communities without lactobacillus dominance is associated with higher levels of proinflammatory cytokines. The group of women in which the bacterial community was composed of a high diversity of species (Sneathia sanguinigens, S. amnii, Mobiluncus mulieris, Prevotella amnii, Aerococcus, and Fusobacterium) presented higher proinflammatory genital cytokine levels. Induction of IL- $1 \alpha$, IL- $1 \beta$, and IL- 8 by these bacteria has also been demonstrated in vitro [58]. In addition, an important increase in IL- $1 \beta$ and TNF- $\alpha$ levels in persistent abnormal vaginal microbiota samples has been demonstrated in vivo [59].
It was postulated that Gram-negative bacterial membrane lipopolysaccharide may be sensed by cervical antigen-presenting cells (APC) inducing TLR4 signaling, NF$\mathrm{kB}$ activation, and the production of proinflammatory cytokines and $\mathrm{T}$-cell chemoattractants. In women with a high Prevotella abundance, a marked response to lipopolysaccharide, IFN- $\gamma$, and IL- $1 \beta$ was observed, probably reflecting an immune response against Gram-negative bacteria. CST IV APC also showed a higher expression of CD80, ICAM-1, and MHC II, contributing to T-cell priming and effector function [58].

On the other hand, cervicovaginal environment modifications may act together with HPV infection, contributing since the early stages of CC and creating, for instance, a local immunosuppression state [60]. Some studies have suggested that certain cervicovaginal microbiota species can modulate the local inflammatory immune response, possibly promoting the expression of immunosuppressive cytokines, and that abnormal vaginal microbiota is related to HPV infection and persistence [61].

Audirac-Chalifour et al. [60] conducted a study to analyze the cervical microbiome and cytokine profiles in various stages of CC. They proposed that, after hrHPV infection of the cervical epithelium, the microbiome composition switches from L. crispatus to L. iners. As the infection progresses to a squamous intraepithelial lesion (SIL), there is an increase in microbiota diversity marked by Sneathia and Fusobacterium spp. In CC, Fusobacterium necrophorum was also present, increasing the microbiome diversity. In this suggested model, HPV infection is responsible for creating an immunosuppressive microenvironment (through IL-10 expression and macrophage type 2 induction) that is enhanced by TGF $\beta-1$ derived from microbiota, creating positive feedback between microbiota and cytokine profile.

CST dominated by Fusobacterium spp. are associated with an immunosuppressive microenvironment, characterized by higher levels of IL- 4 and TGF $\beta-1$ and by a shift from a Th1 to a Th2 immune response. In addition, there is direct interference on the E-cadherin/ $\beta$-catenin signaling pathway on cervical HPV-transformed cells [60]. In the gut, however, F. nucleatum has been shown to exert a proinflammatory and tumorigenic effect [62].

\section{Microbiome, Oxidative Stress, and Cervical \\ Alterations}

Oxidative stress, which reflects an imbalance of the intracellular redox state due to an excess of reactive oxygen species (ROS) production over to the antioxidant system may also be a consequence of dysbiosis [63-65]. ROS, in- 
cluding the superoxide radical anion $\left(\mathrm{O}_{2}{ }^{--}\right)$, the hydroxyl radical $\left(\mathrm{OH}^{*}\right)$, and hydrogen peroxide $\left(\mathrm{H}_{2} \mathrm{O}_{2}\right)$, can play a beneficial role as well as a harmful role in biological systems. These species can have important functions in regulation of cellular signaling pathways, such apoptosis and immune defense against infectious agents. However, the accumulation of ROS can lead to oxidative damage on cellular structures and biomolecules, such as proteins, lipids, and DNA $[65,66]$.

Therefore, oxidative stress has been linked to the promotion and progression of several types of tumors, including CC [64, 67]. ROS and reactive nitrogen species play a significant role in HPV-mediated cervical carcinogenesis, since the accumulation of these species can increase the levels of DNA damage, which may allow HPV genome integration and subsequently cell transformation [68]. Viral DNA integration into the host genome frequently promotes disruption of the early viral gene E2, which inhibits E6 and E7 oncogenes expression. The result is an uncontrolled expression of HPV E6/E7 proteins that leads to increased cellular proliferation and decreased apoptosis [9, 20, 69].

Although there are studies that associate oxidative stress $[64,67]$ and VMB $[11,20,70,71]$ with CC, the association between oxidative stress and the VMB is under discussion in the literature. Chen et al. [72] observed that the levels of $\mathrm{H}_{2} \mathrm{O}_{2}$ in women with $\mathrm{BV}$ were almost 10 times higher than those in healthy patients, which suggests that oxidative stress was formed in these patients. In contrast, Piyathilake et al. [73], analyzing women with HPV-positive CIN, hypothesized that the cervicovaginal microbiome could induce oxidative DNA damage. However, no association was observed between microbiome diversity and oxidative DNA damage, as measured by the presence of 8-hydroxy-2'-deoxyguanosine (8-OHdG), a biomarker of oxidative stress-induced DNA damage.

Vaginal health has been attributed to the presence of Lactobacillus $\mathrm{H}_{2} \mathrm{O}_{2}$-producing species/strains, since some epidemiological studies have reported a possible protective effect of $\mathrm{H}_{2} \mathrm{O}_{2}$ against $\mathrm{BV}$ and other transmitted infections, such as HIV-1 [74-80]. Besides Lactobacillus spp. (except Lactobacillus iners), leukocytes and endothelial and cervical transformed cells, among others, can also generate hydrogen peroxide. One of the mechanisms of $\mathrm{H}_{2} \mathrm{O}_{2}$ production is dismutation of $\mathrm{O}_{2}{ }^{\cdot-}$ (produced by NADPH oxidase) into $\mathrm{H}_{2} \mathrm{O}_{2}$, which can occur spontaneously, optimally at $\mathrm{pH} 4.8$, or catalyzed by SOD enzymes (superoxide dismutase) [80, 81].

Moreover, myeloperoxidase (MPO), an enzyme expressed by polymorphonuclear neutrophils and macro- phages, is responsible for the reaction of halides (e.g., $\mathrm{Cl}^{-}$) and $\mathrm{H}_{2} \mathrm{O}_{2}$, producing hypochlorous acid $(\mathrm{HOCl})$, a type of ROS involved in oxidative burst when an innate immune response is required. Thus, the antimicrobial role of $\mathrm{H}_{2} \mathrm{O}_{2}$ producing lactobacilli has been demonstrated to be efficiently higher in the presence of peroxidase and halides [77, 81-83]. Consequently, it is thought that $\mathrm{HOCl}$ is a powerful antimicrobial compound produced by the $\mathrm{H}_{2} \mathrm{O}_{2}$ /peroxidase/halide system present in phagocytes and tissue fluids $[83,84]$. Interestingly, Klebanoff et al. [77] reported increased concentrations of peroxidase in the vaginal fluids of almost all of the patients analyzed (and sufficient $\mathrm{HOCl}$ production). Additionally, the authors not only observed the antimicrobial effect of $\mathrm{H}_{2} \mathrm{O}_{2}$-producing lactobacilli but also proposed an antitumoral effect of these bacteria.

Krüger and Bauer [83] suggested that the $\mathrm{H}_{2} \mathrm{O}_{2}$ produced by Lactobacillus spp., per se, is not favorable for vaginal epithelial cells, since it induces nonselective apoptosis in transformed and nontransformed cells. On the other hand, the addition of peroxidase allows nontransformed cell protection against the apoptosis mediated by lactobacillus-derived $\mathrm{H}_{2} \mathrm{O}_{2}$. Considering that $\mathrm{HOCl}$ reacts with $\mathrm{O}_{2}{ }^{--}$derived from transformed cells, leading to $\mathrm{OH}^{\bullet}$ production that induces apoptosis [82], it was proposed that there is an association between the presence of $\mathrm{H}_{2} \mathrm{O}_{2}$-producing lactobacilli in VMB and the increased MPO activity, which causes clearance of HPV-infected cells and induces transformed cell apoptosis $[84,85]$.

However, there is no consensus on the protective role of $\mathrm{H}_{2} \mathrm{O}_{2}$ on the cervicovaginal microbiome. Some researchers consider that it is improbable that $\mathrm{H}_{2} \mathrm{O}_{2}$ could have an antimicrobial effect on VMB, since the cervicovaginal environment is hypoxic most of time and lactobacilli require large amounts of $\mathrm{O}_{2}$ to form hydrogen peroxide $[80,86]$. In accordance with this argument, $\mathrm{H}_{2} \mathrm{O}_{2}$ produced by lactobacilli was not detected under hypoxic conditions in cervicovaginal fluid [87] and supernatant of Lactobacillus strains [88]. Moreover, $\mathrm{H}_{2} \mathrm{O}_{2}$ generated by lactobacilli, in physiological concentrations, did not inactivate HSV-2 (herpes simplex virus type 2) or any BVassociated bacteria analyzed in vitro, even when MPO was supplemented [87]. In the same study, it was also observed that cervicovaginal fluid and semen blocked the antimicrobial activity of $\mathrm{H}_{2} \mathrm{O}_{2}$.

Under aerobic conditions, which is used by most studies that observe antimicrobial effects of $\mathrm{H}_{2} \mathrm{O}_{2}$-producing lactobacilli, hydrogen peroxide production rather than lactic acid production is favored. However, when lactobacilli are growing in the absence of oxygen, fermentation can be preferred $[80,86,89]$. Thus, lactic acid was found 
to be produced at higher concentrations under hypoxic conditions $[86,90]$. Additionally, lactic acid can inactivate $\mathrm{BV}$-associated bacteria and Chlamydia trachomatis, which were not observed in the presence of $\mathrm{H}_{2} \mathrm{O}_{2}[91,92]$. Furthermore, $\mathrm{H}_{2} \mathrm{O}_{2}$ could represent a benefic characteristic of lactobacilli or it could be just a marker for lactobacilli strains that protect the cervicovaginal environment for other beneficial causes $[80,86]$.

Further studies are essential to understand the role of oxidative stress on the VMB and how it could contribute to the development and progression of cervical lesions and cancer.

\section{Protective Mechanisms Associated with Lactobacillus}

Lactobacillus spp. predominates in low $\mathrm{pH}$ environments. Vaginal acidity prevents colonization by anaerobes, maintains the cervical epithelial barrier through production of bacteriocins, and acts against mucin degradation, keeping away opportunistic infections [21]. As mentioned before, lactic acid production inhibits the growth of several anaerobic agents associated with sexually transmitted diseases that may contribute to the progression of cervical lesions when associated with hrHPV persistence [93]. Infection by C. trachomatis seems to increase the risk of hrHPV infection of CC through an inflammatory response, which increases ROS production and free radicals [94].

Di Pietro et al. [95] evaluated simultaneous cervical infection by C. trachomatis and HPV and the varieties of associated cervical microbiomes. Women with both infections exhibited a greater bacterial diversity primarily related to the presence of anaerobes such as G. vaginalis, A. vaginae, and, in reduced numbers, Lactobacillus, thus associating dysbiosis with the occurrence of infections. On the other hand, healthy women showed a dominance of Lactobacillus, with anaerobic bacteria representing $<2 \%$ of the cervical flora. Likewise, women infected by $C$. trachomatis alone had a diverse cervical flora but poor levels of Lactobacillus. L. iners was more frequently detected in coinfected women in comparison with healthy ones. Furthermore, it was found that the flora composition of HPV-positive and Chlamydia-negative women did not differ significantly from that of healthy women. Still, in this study L. gasseri was not identified in HPVpositive women, supporting the findings of other authors who related the presence of $L$. gasseri to the clearance of HPV infection [96, 97].
Species of lactobacilli can produce 2 lactic acid isomers, i.e., L- and D-lactic acid. The latter exerts more protective action against vaginal dysbiosis [21]. Besides producing lactic acid, species of Lactobacillus produce peptides with an antimicrobial action, such as bacteriocins and biosurfactants. $L$. iners can synthesize only L-lactic acid and cannot produce hydrogen peroxide, which also exhibits an inhibitory action against bacterial growth [21, 98]. Moreover, L. iners is able to produce inerolysin, a pore-forming cytotoxin, similar to the vaginolysin protein secreted by Gardnerella spp., which forms pores in the vaginal epithelium, favoring infections [98]. Thus, an L. crispatus-dominated VMB is related to maintenance of protective mucosal surface layer integrity and poses a smaller risk of opportunistic bacterial and viral urogenital infections, including by HPV. On the other hand, a VMB dominated by $L$. iners is associated with a greater risk of viral infections and development of precursor lesions and CC [21].

\section{Microbiome, Genital Infection, and Cancer}

Several studies have correlated the different VMB with HPV infection, different grades of CIN, and CC. Mitra et al. [70] evaluated a group of 169 women referred for colposcopy and found an increased bacterial diversity coupled with diminished lactobacilli associated with the severity of the cytological lesion. CST IV was present in $40 \%$ of the women with CC and only in $10 \%$ of those with a normal cytology. On the other hand, CST I was present in $50 \%$ of the cytological examinations and only in $20 \%$ of the CC cases; low levels of $L$. jensenii were related to severe lesions [70].

Some dysbiotic bacterial communities are known to cause immune dysregulation favoring a tumor-promoting microenvironment $[99,100]$. It is known that HPV is necessary but not sufficient to cause CC. In most infected women the immune response is able to control the infection and prevent high-grade lesions and tumors [101]. Among the cofactors in CC development, the VMB may play an important role $[44,102]$.

BV was associated with higher HPV infection rates, suggesting that an increase in the diversity of vaginal bacteria together with a reduction of lactobacilli may contribute to the persistence of HPV infection [44]. G. vaginalis is capable of secreting the enzyme sialidase, which degrades vaginal mucus by cleaving its glycoproteins. One of these proteins is mucin, which provides a physical barrier to the surface of the vaginal mucus [21]. Further- 
more, the bacteria present in CST IV are also capable of producing butyric acid, which can regulate histone acetylation. The epigenetic regulation promoted by the metabolite favors reactivation of the latent HIV-1 virus, indicating a potential involvement of VMB in AIDS progression [103]. Still, women with CST IV exhibit an increase in the production of proinflammatory cytokines and in the recruitment of CD4+ and CCR5+ cells activated to the vaginal mucus, favoring the acquisition of HIV [28].

Kwasniewski et al. [44] assessed the vaginal flora of 250 women, including 70 healthy controls, 95 women with low-grade SIL and HPV positivity, and 85 women with high-grade SIL and HPV positivity. In the control group, high levels of L. crispatus, L. iners, and L. taiwanensis and an absence of $G$. vaginalis and L. acidophilus were detected. In the low-grade-SIL group, L. crispatus was less frequent than in the control group and L. acidophilus and $L$. iners predominated. On the other hand, in the highgrade-SIL group, G. vaginalis and L. acidophilus were increased, while the frequencies of L. iners, L. crispatus, and $L$. taiwanensis were lower than in the control group. These results show a possible relationship between the VMB, HPV infection, and CIN development. A microbiome dominated by $G$. vaginalis and poor in $L$. iners, $L$. crispatus, and L. taiwanensis may be a cofactor for HPV persistence, CIN development, and CC [44].

Di Paola et al. [104] evaluated the VBM of women positive for HPV DNA, and after 1 year of treatment they reassessed them with new viral genotyping. Interestingly, the study classified CST IV into 2 categories, i.e., CST IVBV and CST IV-AV. CST IV-BV was composed, predominantly, of anaerobic bacteria such as Gardnerella, Prevotella, Atopobium, Sneathia, and (scarce) Lactobacillus species. On the other hand, the CST IV-AV group was composed of aerobic and anaerobic bacteria, such as Pseudomonas, Brevibacterium, Peptostreptococcus, Enterococcus, Streptococcus, Propionibacterium, Bifidobacterium, and Shigella species. In the women with persistent HPV infection, the dominant VMB was formed by anaerobes (CST IV-BV) and scarce lactobacilli, and in the women with a cleared HPV infection there was a prevalence of CST IV-AV. The controls had a dominance of lactobacilli [104]. These data correlate flora deficient in lactobacilli with a greater risk of HPV infection and the presence of BV with a smaller chance of clearance of the viral infection [104, 105]. Hence, different lactobacilli play distinctive roles. A VMB dominated by L. crispatus is associated with a lower risk of infection by HPV, CIN, and CC, whereas a VBM dominated by L. iners is associ- ated with a higher risk of being infected by such agents [106].

Cervical precancer lesions that regress, compared to those that progress to cancer, harbor a different immune microenvironment [107]. Specific bacteria, such as Gardnerella, and a rise in microbiological diversity may be used as biomarkers of cervical changes to identify women with a high risk of developing persistent HPV infection, CIN, and cancer [108].

\section{Are Probiotics a Therapeutic Option for HPV?}

According to the World Health Organization, probiotics are "live microorganisms which when administered in adequate amounts confer a health benefit on the host" [109]. The species of Bifidobacterium, Lactobacillus, and Streptococcus are capable of altering the host's microbiome, improving the immune response and the inflammatory state [110].

Probiotics containing species of lactobacilli have been used in the treatment of urogenital infections to improve the vaginal flora. The mechanism of action would involve vaginal acidification, prevention of bacterial adhesion, and synergistic action with the host's immune system [110]. Although there are no conclusive data on their efficacy, probiotics seem to be an alternative complementary treatment of BV and sexually transmitted diseases given that they do not induce inflammation, promote resistance, or have adverse effects [111].

The effects of probiotics on cytological alterations of the uterine cervix and on HPV infection were evaluated by Verhoeven et al. [112] in 51 individuals. Twenty-four women received the Yakult ${ }^{\circledR}$ probiotic, which contains $L$. paracasei strain Shirota, daily, and 27 women made up the control group. At baseline all women had a positive PCR for HPV. After 3 months, HPV had cleared in 25\% of the women who ingested the probiotic against $7.7 \%$ of the control group. After 6 months, the clearance rates were 29.2 and $19.2 \%$ in the probiotic and control groups, respectively. Still, in the same study, the HPV-infectionrelated cytological abnormality clearance was twice as high in the probiotic group than in the control group [112].

Palma et al. [113] assessed 117 women with BV or fungus infection (with cytological changes or presence of $\mathrm{HPV} / \mathrm{PCR}$ ). Women were divided in 2 groups and received a vaginal capsule of L. rhamnosus BMX 54 following treatment of the infections. Group $1(n=60)$ received probiotics for 3 months and group $2(n=57)$ received 
probiotics for 6 months. After 3 and 6 months, samples were collected for cytology, colposcopy, and bacterioscopy, as well as for investigation of fungi and vaginosis. After 9 months, analyses of HPV/PCR were included. The results indicated that the clearance of cytological changes was 2 -fold in group 2, which used the probiotic for a longer period. Clearance of the HPV infection was also greater in group 2 (i.e., $31.2 \%$ vs. $11.6 \%$ in group 1), which also had lower relapse rates of vaginal infection [113]. Additional longitudinal studies are needed to understand whether CC and lesions outcomes are associated with the constitution of the VMB.

\section{Conclusion}

Studies conducted during the last decade have evidenced the variable and complex composition of the VMB. Persistent HPV infection with hrHPV types is the main risk factor for the development of almost all CC and a significant proportion of vaginal and vulvar malignancies. Recent data suggest that the presence and abundance of some bacterial species may prevent HPV infection and contribute to virus clearance reducing the risk of development of cancer precursor lesions at these anatomic sites. Conversely, other bacterial types may promote the pathological state. Therefore, understanding the impact of the VMB composition and its alterations (dysbiosis) on HPV infection/persistence may contribute to a better predic- tion of the outcomes of infections by this virus. Moreover, clear identification of the bacterial components associated with HPV-caused pathologies may have a clinical relevance and provide an opportunity for alternative therapeutic strategies. Presently available technologies allow the rapid high-throughput analysis of VMB. These tools should be applied in longitudinal studies to determine the involvement of specific bacterial species in the establishment, prevention, progression, or regression of HPV-related cervical, vaginal, and vulvar pathologies.

\section{Conflict of Interest Statement}

The authors have no conflict of interests to declare.

\section{Funding Sources}

This research was supported by the Fundação de Amparo à Pesquisa do Estado de São Paulo (FAPESP; FAPESP 2015/265732).

\section{Author Contributions}

L.T. conceived, organized, and revised this review. C.P.C., M.L.S., and R.A.L.N. gathered information from the literature and prepared this paper. N.P.C.L. assisted in the discussion for this review. All of the authors read and approved the final version of this paper.

\section{References}

1 Ferlay J, Ervik M, Lam F, Colombet M, Mery L, Piñeros M, et al. Global Cancer Observatory: Cancer Today [Internet]Lyon, France: International Agency for Research on Cancer; 2018.

2 World Health Organization (WHO). Human papillomavirus (HPV) and cervical cancer [Internet]. 2019.

3 Zhou C, Tuong ZK, Frazer IH. Papillomavirus Immune Evasion Strategies Target the Infected Cell and the Local Immune System. Front Oncol. 2019 Aug;9(August):682.

4 Cohen PA, Jhingran A, Oaknin A, Denny L. Cervical cancer. Lancet. 2019 Jan;393(10167): 169-82.

5 Graham SV. The human papillomavirus replication cycle, and its links to cancer progression: a comprehensive review. Clin Sci (Lond). 2017 Aug;131(17):2201-21.

6 Bosch FX, de Sanjosé S. Chapter 1: human papillomavirus and cervical cancer-burden and assessment of causality. J Natl Cancer Inst Monogr. 2003;2003(31):3-13.
7 Giuliano AR, Tortolero-Luna G, Ferrer E, Burchell AN, de Sanjose S, Kjaer SK, et al. Epidemiology of human papillomavirus infection in men, cancers other than cervical and benign conditions. Vaccine. 2008 Aug;26(10 Suppl 10):K17-28.

8 Castellsagué X. Natural history and epidemiology of HPV infection and cervical cancer. Gynecol Oncol. 2008 Sep;110(3 Suppl 2):S4-7.

9 Kyrgiou M, Mitra A, Moscicki AB. Does the vaginal microbiota play a role in the development of cervical cancer? Transl Res. 2017 Jan; 179(4):168-82.

10 Chase D, Goulder A, Zenhausern F, Monk B, Herbst-Kralovetz $\mathrm{M}$. The vaginal and gastrointestinal microbiomes in gynecologic cancers: a review of applications in etiology, symptoms and treatment. Gynecol Oncol. 2015 Jul;138(1):190-200.

11 Champer M, Wong AM, Champer J, Brito IL, Messer PW, Hou JY, et al. The role of the vaginal microbiome in gynaecological cancer. BJOG. 2018 Feb;125(3):309-15.
12 Foster KR, Schluter J, Coyte KZ, Rakoff-Nahoum S. The evolution of the host microbiome as an ecosystem on a leash. Nature. 2017 Aug;548(7665):43-51.

13 Backhed F, Ley RE, Sonnenburg JL, Peterson DA, Gordon JI. Host-bacterial mutualism in the human intestine. Science. 2005 Mar 25. 307(5717):1915-20.

14 Lederberg BJ, McCray AT. 'Ome sweet' omics: A genealogical treasury of words. Science. 2001;15(7):8.

15 Peterson J, Garges S, Giovanni M, McInnes P, Wang L, Schloss JA, et al.; NIH HMP Working Group. The NIH Human Microbiome Project. Genome Res. 2009 Dec;19(12):231723.

16 Liu MB, Xu SR, He Y, Deng GH, Sheng HF, Huang XM, et al. Diverse vaginal microbiomes in reproductive-age women with vulvovaginal candidiasis. PLoS One. 2013 Nov; 8(11):e79812. 
17 Łaniewski P, Ilhan ZE, Herbst-Kralovetz MM. The microbiome and gynaecological cancer development, prevention and therapy. Nat Rev Urol. 2020 Apr;17(4):232-50.

18 Ravel J, Gajer P, Abdo Z, Schneider GM, Koenig SS, McCulle SL, et al. Vaginal microbiome of reproductive-age women. Proc Natl Acad Sci USA. 2011 Mar; 108(Suppl 1):4680-7.

19 Romero R, Hassan SS, Gajer P, Tarca AL, Fadrosh DW, Nikita L, et al. The composition and stability of the vaginal microbiota of normal pregnant women is different from that of non-pregnant women. Microbiome. 2014 Feb;2(1):4.

20 Mitra A, MacIntyre DA, Marchesi JR, Lee YS, Bennett PR, Kyrgiou M. The vaginal microbiota, human papillomavirus infection and cervical intraepithelial neoplasia: what do we know and where are we going next? Microbiome. 2016 Nov;4(1):58.

21 Amabebe E, Anumba DO. The Vaginal Microenvironment: The Physiologic Role of Lactobacilli. Front Med (Lausanne). 2018 Jun; 5:181.

22 Rousseau V, Lepargneur JP, Roques C, Remaud-Simeon M, Paul F. Prebiotic effects of oligosaccharides on selected vaginal lactobacilli and pathogenic microorganisms. Anaerobe. 2005 Jun;11(3):145-53.

23 Zhou X, Brown CJ, Abdo Z, Davis CC, Hansmann MA, Joyce P, et al. Differences in the composition of vaginal microbial communities found in healthy Caucasian and black women. ISME J. 2007 Jun;1(2):121-33.

24 Koumans EH, Sternberg M, Bruce C, McQuillan G, Kendrick J, Sutton M, et al. The prevalence of bacterial vaginosis in the United States, 2001-2004; associations with symptoms, sexual behaviors, and reproductive health. Sex Transm Dis. 2007 Nov;34(11): 864-9.

25 Łaniewski P, Barnes D, Goulder A, Cui H, Roe DJ, Chase DM, et al. Linking cervicovaginal immune signatures, HPV and microbiota composition in cervical carcinogenesis in non-Hispanic and Hispanic women. Sci Rep. 2018;8(1):7593

26 Green KA, Zarek SM, Catherino WH. Gynecologic health and disease in relation to the microbiome of the female reproductive tract. Fertil Steril. 2015 Dec;104(6):1351-7.

27 Chico RM, Mayaud P, Ariti C, Mabey D, Ronsmans C, Chandramohan D. Prevalence of malaria and sexually transmitted and reproductive tract infections in pregnancy in sub-Saharan Africa: a systematic review. JAMA. 2012 May;307(19):2079-86.

28 Gosmann C, Anahtar MN, Handley SA, Farcasanu M, Abu-Ali G, Bowman BA, et al. Lactobacillus-Deficient Cervicovaginal Bacterial Communities Are Associated with Increased HIV Acquisition in Young South African Women. Immunity. 2017 Jan;46(1):29-37.

29 Jespers V, Crucitti T, Menten J, Verhelst R, Mwaura M, Mandaliya K, et al. Prevalence and Correlates of Bacterial Vaginosis in Different Sub-Populations of Women in Sub-Sa- haran Africa: A Cross-Sectional Study. PLoS One. 2014 Oct;9(10):e109670.

30 Torcia MG. Interplay among Vaginal Microbiome, Immune Response and Sexually Transmitted Viral Infections. Int J Mol Sci. 2019 Jan;20(2):266.

31 Spear GT, French AL, Gilbert D, Zariffard MR, Mirmonsef P, Sullivan TH, et al. Human $\alpha$-amylase present in lower-genital-tract mucosal fluid processes glycogen to support vaginal colonization by Lactobacillus. J Infect Dis. 2014 Oct;210(7):1019-28.

32 Bradley F, Birse K, Hasselrot K, Noël-Romas $\mathrm{L}$, Introini A, Wefer $\mathrm{H}$, et al. The vaginal microbiome amplifies sex hormone-associated cyclic changes in cervicovaginal inflammation and epithelial barrier disruption. Am J Reprod Immunol. 2018 Jul;80(1):e12863.

33 Vodstrcil LA, Hocking JS, Law M, Walker S, Tabrizi SN, Fairley CK, et al. Hormonal contraception is associated with a reduced risk of bacterial vaginosis: a systematic review and meta-analysis. PLoS One. 2013 Sep; 8(9):e73055.

34 Jespers V, van de Wijgert J, Cools P, Verhelst R, Verstraelen H, Delany-Moretlwe S, et al.; Vaginal Biomarkers Study Group. The significance of Lactobacillus crispatus and L. vaginalis for vaginal health and the negative effect of recent sex: a cross-sectional descriptive study across groups of African women. BMC Infect Dis. 2015 Mar;15(1):115.

35 Schwebke JR, Desmond RA, Oh MK. Predictors of bacterial vaginosis in adolescent women who douche. Sex Transm Dis. 2004 Jul; 31(7):433-6.

36 Prokopczyk B, Cox JE, Hoffmann D, Waggoner SE. Identification of tobacco-specific carcinogen in the cervical mucus of smokers and nonsmokers. J Natl Cancer Inst. 1997 Jun; 89(12):868-73

37 Wei L, Griego AM, Chu M, Ozbun MA. Tobacco exposure results in increased E6 and E7 oncogene expression, DNA damage and mutation rates in cells maintaining episomal human papillomavirus 16 genomes. Carcinogenesis. 2014 Oct;35(10):2373-81.

38 Luhn P, Walker J, Schiffman M, Zuna RE, Dunn ST, Gold MA, et al. The role of co-factors in the progression from human papillomavirus infection to cervical cancer. Gynecol Oncol. 2013 Feb;128(2):265-70.

39 Appleby P, Beral V, Berrington de González A, Colin D, Franceschi S, Goodill A, et al.; International Collaboration of Epidemiological Studies of Cervical Cancer. Carcinoma of the cervix and tobacco smoking: collaborative reanalysis of individual data on 13,541 women with carcinoma of the cervix and 23,017 women without carcinoma of the cervix from 23 epidemiological studies. Int J Cancer. 2006 Mar;118(6):1481-95

40 Brotman RM, He X, Gajer P, Fadrosh D, Sharma E, Mongodin EF, et al. Association between cigarette smoking and the vaginal $\mathrm{mi}$ crobiota: a pilot study. BMC Infect Dis. 2014 Aug;14(1):471.
41 Hill GB. The microbiology of bacterial vaginosis. Am J Obstet Gynecol. 1993 Aug;169(2 Pt 2):450-4.

42 Spiegel CA, Amsel R, Holmes KK. Diagnosis of bacterial vaginosis by direct gram stain of vaginal fluid. J Clin Microbiol. 1983 Jul;18(1): $170-7$.

43 Nugent RP, Krohn MA, Hillier SL. Reliability of diagnosing bacterial vaginosis is improved by a standardized method of gram stain interpretation. J Clin Microbiol. 1991 Feb;29(2): 297-301.

44 Kwasniewski W, Wolun-Cholewa M, Kotarski J, Warchol W, Kuzma D, Kwasniewska A, et al. Microbiota dysbiosis is associated with $\mathrm{HPV}$-induced cervical carcinogenesis. Oncol Lett. 2018 Dec;16(6):7035-47.

45 Dethlefsen L, McFall-Ngai M, Relman DA. An ecological and evolutionary perspective on human-microbe mutualism and disease. Nature. 2007 Oct;449(7164):811-8

46 Taddei CR, Cortez RV, Mattar R, Torloni MR Daher S. Microbiome in normal and pathological pregnancies: A literature overview. Am J Reprod Immunol. 2018 Aug; 80(2):e12993.

47 Borgdorff $\mathrm{H}$, Gautam R, Armstrong SD, Xia D, Ndayisaba GF, Van Teijlingen NH, et al. Cervicovaginal microbiome dysbiosis is associated with proteome changes related to alterations of the cervicovaginal mucosal barrier. Mucosal Immunol. 2016 May;9(3):621-33.

48 Valenti P, Rosa L, Capobianco D, Lepanto MS, Schiavi E, Cutone A, et al. Role of lactobacilli and lactoferrin in the mucosal cervicovaginal defense. Volume 9. Frontiers in Immunology. Frontiers Media S.A.; 2018.

49 Petrova MI, Lievens E, Malik S, Imholz N, Lebeer S. Lactobacillus species as biomarkers and agents that can promote various aspects of vaginal health. Front Physiol. 2015 Mar;6: 81.

50 Al-Nasiry S, Ambrosino E, Schlaepfer M, Morré SA, Wieten L, Voncken JW, et al. The Interplay Between Reproductive Tract Microbiota and Immunological System in Human Reproduction. Front Immunol. 2020 Mar; 11(March):378.

51 Valore EV, Wiley DJ, Ganz T. Reversible deficiency of antimicrobial polypeptides in bacterial vaginosis. Infect Immun. 2006 Oct; 74(10):5693-702.

52 Smith SB, Ravel J. The vaginal microbiota, host defence and reproductive physiology. J Physiol. 2017 Jan;595(2):451-63.

53 Nasioudis D, Beghini J, Bongiovanni AM, Giraldo PC, Linhares IM, Witkin SS. a-Amylase in Vaginal Fluid: Association With Conditions Favorable to Dominance of Lactobacillus. Reprod Sci. 2015 Nov;22(11): 1393-8.

54 Balkus J, Agnew K, Lawler R, Mitchell C, Hitti J. Effects of pregnancy and bacterial vaginosis on proinflammatory cytokine and secretory leukocyte protease inhibitor concentrations in vaginal secretions. J Pregnancy. 2010; 2010:385981. 
55 Lin GG, Scott JG. Bacterial vaginosis and the cervicovaginal immune response. Am J Reprod Immunol. 2012;100(2):130-4.

56 Hearps AC, Tyssen D, Srbinovski D, Bayigga L, Diaz DJ, Aldunate M, et al. Vaginal lactic acid elicits an anti-inflammatory response from human cervicovaginal epithelial cells and inhibits production of pro-inflammatory mediators associated with HIV acquisition. Mucosal Immunol. 2017 Nov;10(6):1480-90.

57 Delgado-Diaz DJ, Tyssen D, Hayward JA, Gugasyan R, Hearps AC, Tachedjian G. Distinct Immune Responses Elicited From Cervicovaginal Epithelial Cells by Lactic Acid and Short Chain Fatty Acids Associated With Optimal and Non-optimal Vaginal Microbiota. Front Cell Infect Microbiol. 2020 Jan;9:446.

58 Anahtar MN, Byrne EH, Doherty KE, Bowman BA, Yamamoto HS, Soumillon M, et al. Cervicovaginal bacteria are a major modulator of host inflammatory responses in the female genital tract. Immunity. 2015 May; 42(5):965-76.

59 Thurman AR, Kimble T, Herold B, Mesquita PM, Fichorova RN, Dawood HY, et al. Bacterial Vaginosis and Subclinical Markers of Genital Tract Inflammation and Mucosal Immunity. AIDS Res Hum Retroviruses. 2015 Nov;31(11):1139-52.

60 Audirac-Chalifour A, Torres-Poveda K, Bahena-Román M, Téllez-Sosa J, Martínez-Barnetche J, Cortina-Ceballos B, et al. Cervical microbiome and cytokine profile at various stages of cervical cancer: A pilot study. PLoS One. 2016 Apr;11(4):e0153274.

61 Gao W, Weng J, Gao Y, Chen X. Comparison of the vaginal microbiota diversity of women with and without human papillomavirus infection: a cross-sectional study. BMC Infect Dis. 2013 Jun;13(1):271.

62 Kostic AD, Chun E, Robertson L, Glickman JN, Gallini CA, Michaud M, et al. Fusobacterium nucleatum potentiates intestinal tumorigenesis and modulates the tumor-immune microenvironment. Cell Host Microbe. 2013 Aug;14(2):207-15.

63 Holmes KK, Chen KC, Lipinski CM, Eschenbach DA. Vaginal redox potential in bacterial vaginosis (nonspecific vaginitis). J Infect Dis. 1985 Aug;152(2):379-82.

64 Klaunig JE. Oxidative Stress and Cancer. Curr Pharm Des. 2018;24(40):4771-8.

65 Ebrahimi S, Soltani A, Hashemy SI. Oxidative stress in cervical cancer pathogenesis and resistance to therapy. J Cell Biochem. 2018 Nov; 120(5):6868-77.

66 Valko M, Rhodes CJ, Moncol J, Izakovic M, Mazur M. Free radicals, metals and antioxidants in oxidative stress-induced cancer. Chem Biol Interact. 2006 Mar;160(1):1-40.

67 Prasad S, Gupta SC, Tyagi AK. Reactive oxygen species (ROS) and cancer: role of antioxidative nutraceuticals. Cancer Lett. 2017 Feb; 387:95-105

68 Williams VM, Filippova M, Filippov V, Payne KJ, Duerksen-Hughes P. Human papillomavirus type $16 \mathrm{E} 6 *$ induces oxidative stress and
DNA damage. J Virol. 2014 Jun;88(12):675161.

69 Woodman CB, Collins SI, Young LS. The natural history of cervical HPV infection: unresolved issues. Nat Rev Cancer. 2007 Jan;7(1): $11-22$.

70 Mitra A, MacIntyre DA, Lee YS, Smith A, Marchesi JR, Lehne B, et al. Cervical intraepithelial neoplasia disease progression is associated with increased vaginal microbiome diversity. Sci Rep. 2015 Nov;5(October): 16865.

71 Curty G, de Carvalho PS, Soares MA. The role of the cervicovaginal microbiome on the genesis and as a biomarker of premalignant cervical intraepithelial neoplasia and invasive cervical cancer. Int J Mol Sci. 2019 Dec; 21(1):E222

72 Chen Z, Zhang Z, Zhang H, Xie B. Analysis of the oxidative stress status in nonspecific vaginitis and its role in vaginal epithelial cells apoptosis. Biomed Res Int. 2015;2015.

73 Piyathilake CJ, Ollberding NJ, Kumar R, Macaluso M, Alvarez RD, Morrow CD. Cervical Microbiota Associated with Higher Grade Cervical Intraepithelial Neoplasia in Women Infected with High-Risk Human Papillomaviruses. Cancer Prev Res (Phila). 2016 May; 9(5):357-66.

74 Antonio MA, Hawes SE, Hillier SL. The identification of vaginal Lactobacillus species and the demographic and microbiologic characteristics of women colonized by these species. J Infect Dis. 1999 Dec;180(6):1950-6.

75 Eschenbach DA, Davick PR, Williams BL, Klebanoff SJ, Young-Smith K, Critchlow CM, et al. Prevalence of hydrogen peroxide-producing Lactobacillus species in normal women and women with bacterial vaginosis. J Clin Microbiol. 1989 Feb;27(2):251-6.

76 Hawes SE, Hillier SL, Benedetti J, Stevens CE, Koutsky LA, Wølner-Hanssen P, et al. Hydrogen peroxide-producing lactobacilli and acquisition of vaginal infections. J Infect Dis. 1996 Nov;174(5):1058-63.

77 Klebanoff SJ, Hillier SL, Eschenbach DA, Waltersdorph AM. Control of the microbial flora of the vagina by $\mathrm{H} 2 \mathrm{O} 2$-generating lactobacilli. J Infect Dis. 1991 Jul;164(1):94-100.

78 Klebanoff SJ, Coombs RW. Viricidal effect of Lactobacillus acidophilus on human immunodeficiency virus type 1: possible role in heterosexual transmission. J Exp Med. 1991 Jul; 174(1):289-92.

79 Cherpes TL, Hillier SL, Meyn LA, Busch JL, Krohn MA. A delicate balance: risk factors for acquisition of bacterial vaginosis include sexual activity, absence of hydrogen peroxideproducing lactobacilli, black race, and positive herpes simplex virus type 2 serology. Sex Transm Dis. 2008 Jan;35(1):78-83.

80 Vaneechoutte $\mathrm{M}$. The human vaginal microbial community. Res Microbiol. 2017 Nov Dec;168(9-10):811-25.

81 Klebanoff SJ. Myeloperoxidase: friend and foe. J Leukoc Biol. 2005 May;77(5):598-625.

82 Matos A, da Silva AP, Medeiros R, Bicho M, Bicho MC. Microenvironment in Vagina as a Key-Player on Cervical Cancer: Interaction of Polymorphic Genetic Variants and Vaginal Microbiome as Co-Factors. Cervical Cancer - Screening. Treatment and Prevention - Universal Protocols for Ultimate Control. InTech; 2018.

83 Krüger H, Bauer G. Lactobacilli enhance reactive oxygen species-dependent apoptosis-inducing signaling. Redox Biol. 2017 Apr;11: 715-24.

84 Castelão C, da Silva AP, Matos A, Inácio Â, Bicho M, Medeiros R, et al. Association of myeloperoxidase polymorphism (G463A) with cervix cancer. Mol Cell Biochem. 2015 Jun;404(1-2):1-4.

85 Bauer G. Lactobacilli-mediated control of vaginal cancer through specific reactive oxygen species interaction. Med Hypotheses. 2001 Aug;57(2):252-7.

86 Tachedjian G, O'Hanlon DE, Ravel J. The implausible "in vivo" role of hydrogen peroxide as an antimicrobial factor produced by vaginal microbiota. Microbiome. 2018 Feb;6(1): 29.

87 O'Hanlon DE, Lanier BR, Moench TR, Cone RA. Cervicovaginal fluid and semen block the microbicidal activity of hydrogen peroxide produced by vaginal lactobacilli. BMC Infect Dis. 2010 May;10(1):120.

88 Ocaña VS, Pesce de Ruiz Holgado AA, NaderMacías ME. Selection of vaginal $\mathrm{H} 2 \mathrm{O} 2$-generating Lactobacillus species for probiotic use. Curr Microbiol. 1999 May;38(5):279-84.

89 Tachedjian G, Aldunate M, Bradshaw CS, Cone RA. The role of lactic acid production by probiotic Lactobacillus species in vaginal health. Res Microbiol. 2017 Nov - Dec;168(910):782-92.

90 O'Hanlon DE, Moench TR, Cone RA. Vaginal $\mathrm{pH}$ and microbicidal lactic acid when lactobacilli dominate the microbiota. PLoS One. 2013 Nov; 8(11):e80074.

91 Gong Z, Luna Y, Yu P, Fan H. Lactobacilli inactivate Chlamydia trachomatis through lactic acid but not H2O2. PLoS One. 2014 Sep; 9(9):e107758

92 O'Hanlon DE, Moench TR, Cone RA. In vaginal fluid, bacteria associated with bacterial vaginosis can be suppressed with lactic acid but not hydrogen peroxide. BMC Infect Dis. 2011 Jul;11(1):200.

93 Robial R, Longatto-Filho A, Roteli-Martins CM, Silveira MF, Stauffert D, Ribeiro GG, et al. Frequency of Chlamydia trachomatis infection in cervical intraepithelial lesions and the status of cytological p16/Ki-67 dual-staining. Infect Agent Cancer. 2017 Jan;12(1):3.

94 Zhu H, Shen Z, Luo H, Zhang W, Zhu X. Chlamydia Trachomatis Infection-Associated Risk of Cervical Cancer: A Meta-Analysis. Medicine (Baltimore). 2016 Mar; 95(13):e3077

95 Di Pietro M, Filardo S, Porpora MG, Recine N, Latino MA, Sessa R. HPV/Chlamydia trachomatis co-infection: metagenomic analysis of cervical microbiota in asymptomatic women. New Microbiol. 2018 Jan;41(1):34-41. 
96 Shannon B, Yi TJ, Perusini S, Gajer P, Ma B, Humphrys MS, et al. Association of HPV infection and clearance with cervicovaginal immunology and the vaginal microbiota. Mucosal Immunol. 2017 Sep;10(5):1310-9.

97 Brotman RM, Shardell MD, Gajer P, Tracy JK, Zenilman JM, Ravel J, et al. Interplay Between the Temporal Dynamics of the Vaginal Microbiota and Human Papillomavirus Detection. J Infect Dis. 2014 Dec 1;210(11): 1723-33.

98 Petrova MI, Reid G, Vaneechoutte M, Lebeer S. Lactobacillus iners: friend or Foe? Trends Microbiol. 2017 Mar;25(3):182-91.

99 Garrett WS. Cancer and the microbiota. Science. 2015 Apr 3;348(6230):80-6.

100 Schwabe RF, Jobin C. The microbiome and cancer. Nat Rev Cancer. 2013 Nov;13(11): 800-12.

101 Insinga RP, Perez G, Wheeler CM, Koutsky LA, Garland SM, Leodolter S, et al.; FUTURE I Investigators. Incident cervical HPV infections in young women: transition probabilities for CIN and infection clearance. Cancer Epidemiol Biomarkers Prev. 2011 Feb;20(2):287-96.

102 Guijon F, Paraskevas M, Rand F, Heywood E, Brunham R, McNicol P. Vaginal microbial flora as a cofactor in the pathogenesis of uterine cervical intraepithelial neoplasia. Int J Gynaecol Obstet. 1992 Mar;37(3):185-91.
103 Imai K, Ochiai K. Effect of microbial coinfection with HIV-1 and butyric acid-producing anaerobic bacteria on AIDS progression. J Oral Biosci. 2013 May;55(2):55-60.

104 Di Paola M, Sani C, Clemente AM, Iossa A, Perissi E, Castronovo G, et al. Characterization of cervico-vaginal microbiota in women developing persistent high-risk Human Papillomavirus infection. Sci Rep. 2017 Aug; 7(1): 10200

105 Brusselaers N, Shrestha S, van de Wijgert J, Verstraelen H. Vaginal dysbiosis and the risk of human papillomavirus and cervical cancer: systematic review and meta-analysis. Am J Obstet Gynecol. 2019 Jul;221(1):9-18. e8.

106 Norenhag J, Du J, Olovsson M, Verstraelen $\mathrm{H}$, Engstrand L, Brusselaers N. The vaginal microbiota, human papillomavirus and cervical dysplasia: a systematic review and network meta-analysis. BJOG. 2020 Jan;127(2): 171-80.

107 Øvestad IT, Gudlaugsson E, Skaland I, Malpica A, Kruse AJ, Janssen EA, et al. Local immune response in the microenvironment of CIN2-3 with and without spontaneous regression. Mod Pathol. 2010 Sep;23(9):123140.
108 Usyk M, Zolnik CP, Castle PE, Porras C, Herrero R, Gradissimo A, et al.; Costa Rica HPV Vaccine Trial (CVT) Group. Cervicovaginal microbiome and natural history of HPV in a longitudinal study. PLoS Pathog. 2020 Mar;16(3):e1008376.

109 Ebner S, Smug LN, Kneifel W, Salminen SJ, Sanders ME. Probiotics in dietary guidelines and clinical recommendations outside the European Union. World J Gastroenterol. 2014 Nov;20(43):16095-100.

110 Li Y, Yu T, Yan H, Li D, Yu T, Yuan T, et al. Vaginal Microbiota and HPV Infection: Novel Mechanistic Insights and Therapeutic Strategies. Infect Drug Resist. 2020 Apr; 13: 1213-20.

111 Reid G. Has knowledge of the vaginal microbiome altered approaches to health and disease? F1000 Res. 2018 Apr;7(0):460.

112 Verhoeven V, Renard N, Makar A, Van Royen P, Bogers JP, Lardon F, et al. Probiotics enhance the clearance of human papillomavirus-related cervical lesions: a prospective controlled pilot study. Eur J Cancer Prev. 2013 Jan;22(1):46-51.

113 Palma E, Recine N, Domenici L, Giorgini M, Pierangeli A, Panici PB. Long-term Lactobacillus rhamnosus BMX 54 application to restore a balanced vaginal ecosystem: a promising solution against HPV-infection. BMC Infect Dis. 2018 Jan;18(1):13. 